\title{
AVALIAÇÃO DA UTILIZAÇÃO DA ENERGIA DE MICRO-ONDAS PARA PROCESSO DE REMOÇÃO DO TEOR DE FÓSFORO CONTIDO NO MINÉRIO DE FERRO
}

\author{
L. M. SILVA ${ }^{1}$ e M. NASCIMENTO \\ Centro de Tecnologia Mineral - Universidade Federal Fluminense \\ leonardouffsilva@gmail.com ${ }^{1}$
}

Artigo submetido em novembro/2013 e aceito em julho/2014

DOI: http://dx.doi.org/10.15628/holos.2014.1754

\section{RESUMO}

O elemento fósforo quando encontrado nos aços em teores acima de $0,04 \%$ torna-se nocivo à qualidade do aço. No processo tradicional de remoção do elemento fósforo contido na gusa, baixos teores somente são obtidos com uso massivo de oxigênio e alto volume de escória, o que torna o processo altamente custoso economicamente e ambientalmente, gerando grandes quantidades de resíduos que devem ser posteriormente tratados. Uma alternativa viável para minimizar os efeitos do fósforo nos processos de obtenção do aço é o prétratamento das frações do minério de alto fósforo logo no seu beneficiamento. $O$ processo de lixiviação ácida é considerado o processo mais econômico para a reação de desfosforação do minério de ferro, todavia dependendo da forma com que o elemento fósforo esteja contido no minério de ferro o mesmo dependerá da adição de energia adicional para sua liberação. O presente trabalho objetiva-se estudar o efeito da energia de micro-ondas na redução do teor de fósforo contido no minério de ferro. Através do método estatístico de delineamento composto central rotacional foi possível identificar as melhores condições de utilização da energia de microondas para redução do teor do elemento fósforo e através da técnica de microscopia eletrônica de varredura (MEV) foi possível analisar a estrutura do minério após seu tratamento com energia de microondas.

PALAVRAS-CHAVE: Redução de fósforo; minério de ferro; lixiviação; micro-ondas.

\section{EVALUATION OF THE USE OF MICROWAVE ENERGY FOR PROCESS OF PHOSPHORUS REMOTION IN IRON ORE}

\section{ABSTRACT}

The phosphorus element when found in steels at levels above $0.04 \%$ becomes detrimental to steel quality. In the traditional process of removing phosphorus contained in pig, low levels are obtained with massive use of oxygen and high slag volume, which makes the process economically and environmentally highly costly generating large quantities of waste that must be subsequently processed. A viable alternative to minimize the effect of phosphorus in the process of obtaining the steel is the pre-treatment of high phosphorus ore fractions during its processing. The process of acid leaching is considered the most economical process for
\end{abstract}

the reaction of dephosphorization iron ore, however regarding on the element phosphorus is contained in the iron ore it will depend on the sum of additional energy for their release. This work aimed to study the effect of microwave energy on reducing the amount of phosphorus contained in iron ore. Through of Statistical method allows us to identify the best conditions for the use of microwave energy to reduce the phosphorus, then by the method of scanning electron microscopy (SEM) was possible to analyze the structure of the ore subsequent treatment with microwave energy.

KEYWORDS: Reduction of phosphorus ; iron ore ; leaching; microwave. 


\section{INTRODUÇÃO}

O minério de ferro é o recurso mineral metálico extraído em maior volume da crosta da Terra. Porém o fósforo é um dos principais elementos prejudiciais à siderurgia, e afeta a qualidade dos produtos de ferro e de aço. O teor do fósforo na composição do aço deve ser menor que 0,05\% sendo que no Brasil e em vários locais do mundo são encontradas grandes quantidades de jazidas de minério de ferro com teores acima de $0,1 \%$ ocorrendo à desvalorização do minério devido ao alto custo decorrente do processamento de redução do teor de fósforo durante o processo de produção do aço. Sendo assim torna-se imprescindível a redução do teor de fósforo presente no minério de ferro antes de seu processamento. O método de remoção de fósforo a partir de minérios de ferro podem envolver processos de fundição, separação física e lixiviação química, sendo constatada a lixiviação química em meio ácido a forma mais viável de redução do teor do elemento fósforo contido no minério de ferro.

Geralmente em depósitos minerais o fosfato primário é a apatita e mais raramente fosfatos de terras raras (monazita e rhabdofânio). Através do processo de intemperismo ocorre a migração do elemento fósforo ocasionando a formação de outros fosfatos nos materiais lateríticos como fosfatos da série da crandallita sendo facilmente removido através do processo de lixiviação química em meio ácido. Todavia o elemento fósforo no minério de ferro pode também existir ligado à molécula de goetita, $\mathrm{FeO}(\mathrm{OH})$, na forma de solução sólida (GRAHAM, 1973). A distribuição de fósforo ao longo dos cristais da goetita impede o uso eficaz das técnicas de separação física, e requer o uso de técnicas de separação química posteriormente ao incremento de energia.

Segundo HAQUE, 1998 foram observados nos minerais presentes no minério de ferro a ocorrencia de diferentes taxas de aquecimento em microondas causando tensões térmicas e fraturas nas partículas de minério de ferro.

Considerando exposto este trabalho pretende demonstrar e avaliar os efeitos do aquecimento do minério de ferro, através da energia de micro-ondas, sobre a remoção do fósforo em minério de ferro.

\section{MATERIAIS E MÉTODOS}

As amostras de minério de ferro são originarias da região do Quadrilátero Ferrífero em Minas Gerais, Brasil. Todas as amostras foram esmagadas e trituradas, gerando tamanhos granulométricos de $28,35,48$ e 200 mesh.

A análise química foi realizada utilizando o método de espectrometria de emissão óptica com plasma indutivamente acoplado realizado no Centro de Tecnologia Mineral, Brasil, onde o qual indicou o teor de fósforo na amostra de minério sendo de $346 \mathrm{mg} / \mathrm{kg}$ o que corresponde a 0,0346\%. O processo de difração de Raio $x$ foi realizado no Centro de Tecnologia Mineral, Brasil, com o objetivo de identificar e quantificar as fases minerais presentes no minério de ferro.

Análises de microscopia eletronica de varredura foram realizadas na Universdade Federal Fluminense. A quantificação da temperatura das amostras estudadas foram realizadas através de imagens da câmera termográfica modelo FLIR T650sc.

Na Figura 1 é demonstrado o espectro por difração de Raios $x$ da amostra de minério de ferro. 


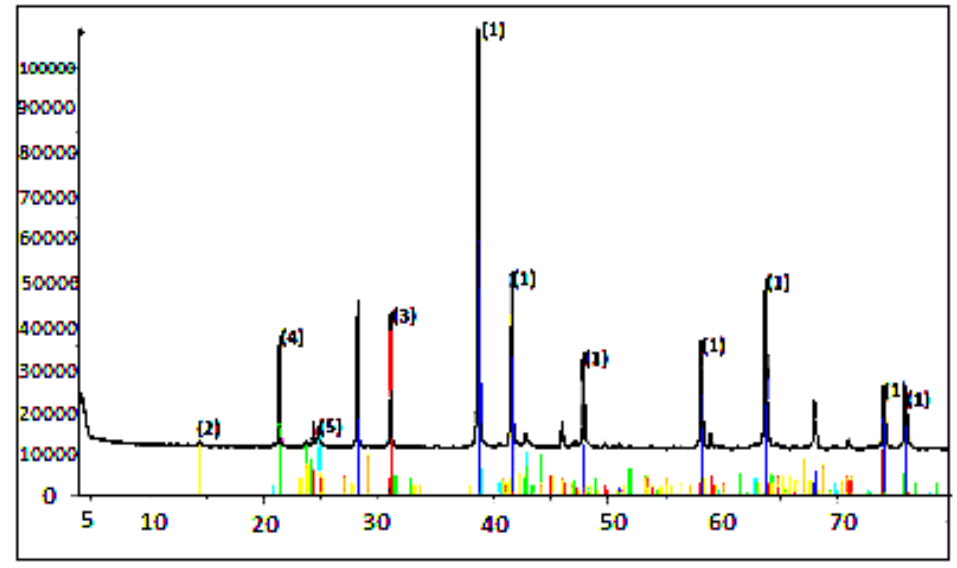

Figura 1. Difração padrão de Raios - $X$ da amostra de minério de ferro.

Na Figura 1 é demonstrado o espectro de Difração de Raio X com diferentes intensidades de sinais para diferentes frações minerais. Foi observado que o minério é composto principalmente de caulinita $4,64 \%$, gibbsita $3,18 \%$, goethita $7,25 \%$, hematita $72,89 \%$, e quartzo $12,05 \%$ como demonstrado na Tabela 1 . A ausencia de compostos fosfatados aluminosos indica que o fósforo ocorre na estrutura da goetita formando um complexo estável.

Tabela 1. Composição química da amostra de minério de ferro (\% em frações mássicas)

\begin{tabular}{|c|c|}
\hline MINERAL & FRAÇÂO MÁSSICA, \% \\
\hline HEMATITA $\left(\mathrm{Fe}_{2} \mathrm{O}_{3}\right)(1)$ & 72,89 \\
\hline CAULINITA $\left[\mathrm{Al}_{2} \mathrm{Si}_{2} \mathrm{O}_{5}(\mathrm{OH})_{4 .}\right]$ & 4,64 \\
\hline QUARTZO $\left(\mathrm{SiO}_{2}\right)$ & 12,05 \\
\hline GIBBSITA $\left[\mathrm{AI}(\mathrm{OH})_{3}\right]$ & 3,18 \\
\hline GOETHITA $[\mathrm{FeO}(\mathrm{OH})]$ & 7,25 \\
\hline
\end{tabular}

2.1 Análise Fatorial do Pré-Tratamento do Minério de Ferro Utilizando Energia de Microondas.

Neste trabalho foi utilizado para o processo de aquecimento do minério através da energia de micro-ondas um forno convencional onde o qual possui $800 \mathrm{w}$ de potência e $2450 \mathrm{MHZ}$ de frequência. Quando se utiliza a frequência de $2450 \mathrm{MHz}$, o alinhamento das moléculas e seu retorno ao estado de desordem ocorrem 4,9X109 vezes por segundo, o qual resulta em um aquecimento rápido e eficiente. Todavia o aquecimento devido a este processo depende do tempo de relaxação da amostra, sendo definido como o tempo necessário para ordenar totalmente e desordenar $63 \%$ da amostra. (KRUG, 2004)

Para análise das interações no minério de ferro foram analisadas diferentes variáveis sendo: Tempo; Tamanho granulométrico e Massa. Para orientação das análises das variáveis foi escolhido o planejamento experimental para três variáveis independentes.

Naturalmente num experimento tão pequeno quanto este pode ser mais adequado, em termos de estimação do resíduo, repetir-se ensaios nos quatros pontos fatoriais. No entanto ensaios no ponto central podem fornecer informações úteis sobre o comportamento das respostas entre os níveis inicialmente atribuídos aos fatores podendo também evidenciar a qualidade da repetitividade do processo. Deve-se, portanto repetir ensaios nos pontos fatoriais e realizar alguns ensaios no ponto central. (RODRIGUES, M.I, ANTONIO, F.I, 2005) 
Sendo assim, foi realizado um fatorial completo 23, incluindo 6 pontos axiais e 6 repetições no ponto central, totalizando 20 ensaios. A Tabela 2 apresenta os valores utilizados no planejamento e na Tabela 3 apresenta a variável resposta temperatura.

Tabela 2. Níveis utilizados no planejamento fatorial

\begin{tabular}{l|c|c|c|c|c}
\hline Variáveis & $-1,68$ & -1 & 0 & 1 & $+1,68$ \\
\hline Granulometria média $(\mu \mathrm{m})$ & 230 & 200 & 48 & 35 & 28 \\
\hline Massa $(\mathrm{g})$ & 5 & 10 & 25 & 50 & 75 \\
\hline Tempo (min) & 2 & 4 & 6 & 8 & 10 \\
\hline
\end{tabular}

Tabela 3. Planejamento fatorial e variável resposta.

\begin{tabular}{|c|c|c|c|c|}
\hline Ensaios & $\begin{array}{c}\text { Granulometria } \\
\text { média }\end{array}$ & $\begin{array}{c}\text { Tempo } \\
\text { (min) }\end{array}$ & $\begin{array}{c}\text { Massa } \\
(\mathrm{g})\end{array}$ & $\begin{array}{c}\text { Temperatura } \\
\left({ }^{0} \mathrm{C}\right) \\
\end{array}$ \\
\hline 1 & -1 & -1 & -1 & 202,2 \\
\hline 2 & +1 & -1 & -1 & 211,8 \\
\hline 3 & -1 & +1 & -1 & 205,4 \\
\hline 4 & +1 & +1 & -1 & 344,8 \\
\hline 5 & -1 & -1 & +1 & 379,6 \\
\hline 6 & +1 & -1 & +1 & 637,9 \\
\hline 7 & -1 & +1 & +1 & 969,6 \\
\hline 8 & +1 & +1 & +1 & 1152,4 \\
\hline 9 & $-1,68$ & 0 & 0 & 408,0 \\
\hline 10 & $+1,68$ & 0 & 0 & 1038,9 \\
\hline 11 & 0 & $-1,68$ & 0 & 319,7 \\
\hline 12 & 0 & $+1,68$ & 0 & 986,2 \\
\hline 13 & 0 & 0 & $-1,68$ & 353,1 \\
\hline 14 & 0 & 0 & $+1,68$ & 1050,5 \\
\hline 15 & 0 & 0 & 0 & 673,2 \\
\hline 16 & 0 & 0 & 0 & 691,1 \\
\hline 17 & 0 & 0 & 0 & 581,0 \\
\hline 18 & 0 & 0 & 0 & 643,4 \\
\hline 19 & 0 & 0 & 0 & 778,0 \\
\hline 20 & 0 & 0 & 0 & 801,1 \\
\hline
\end{tabular}

\section{RESULTADOS E DISCUSSÃO}

\subsection{Ocorrência do Fósforo no Minério de Ferro}

Várias teorias têm sido propostas para explicar a existência de fósforo em goethita. No entanto, nenhuma foi capaz de explicar a desfosforização por lixiviação da goetita. Graham, (1973) propôs que fósforo elementar existia em solução sólida com goethita. Dukino, (1997) contestou esta teoria com base no fato da solução sólida intersticial existir apenas se houver a substituição do cátion por outro de tamanho similar ou menor do que o cátion ligado em sua rede e devendo ainda possuir a mesma carga. O tamanho e a valência do fósforo não são adequados para a sua existência em solução sólida com goethita, e é pouco provável que fósforo elementar exista na solução sólida com a goetita.

Um mecanismo mais plausível foi proposto por Morris e Barbour, (1973) e apoiado por Dukino,(1997) envolvendo superfície de adsorção. Foi sugerido que, antes da desidratação do ferro 
Hidratado na goethita, um grupo hidroxila da superfície é substituído por um ligante de fosfato, como mostrado no seguinte o modelo:

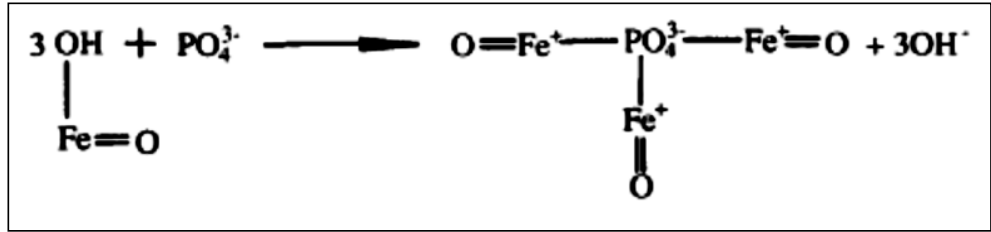

Figura 2. Mecanismo de ocorrencia de fósforo na goetita

Esta teoria é considerada uma provável explicação da existência de fósforo na goethita. Além disso, esta teoria pode ser usada para explicar a desfosforização.

$\mathrm{Na}$ Figura 3 é demonstrado o diagrama de fase do minério de ferro na composição de $\mathrm{Fe}$ $60 \%$, O 20\%, Si 10\%, Al 9,99\%. Calculado utilizando o software Thermocalc ${ }^{\circledR}$.

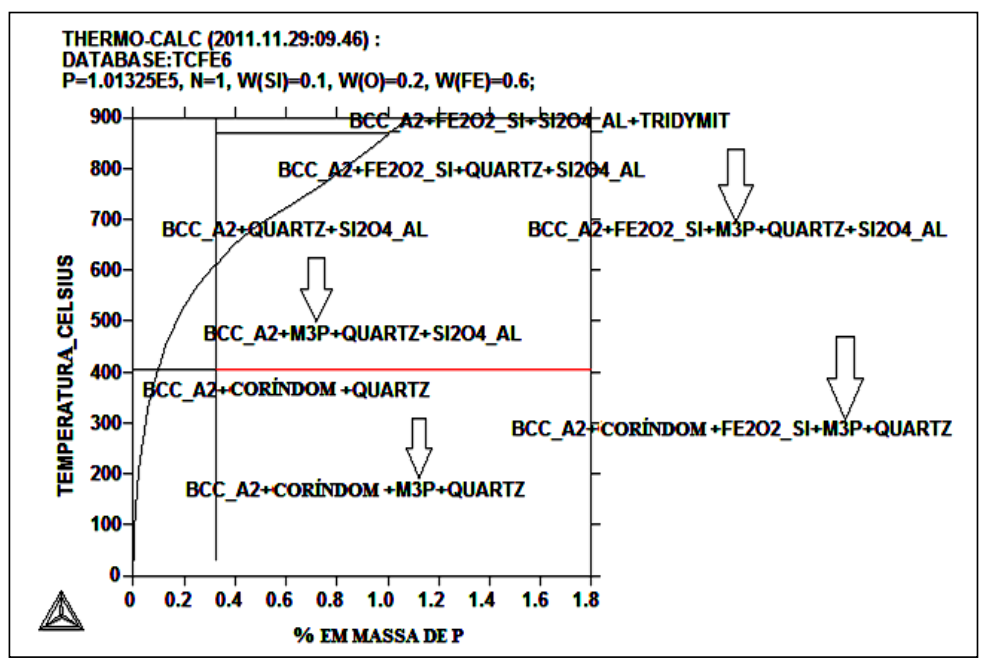

Figura 3. Diagrama de fase do minério de ferro de composição: Fe $60 \%$, O 20\%, Si 10\%, Al 9,99\%. Calculado utilizando o software Thermocalc ${ }^{\circledR}$.

Na Figura 3 é demonstrado o diagrama de fase do minero de ferro em diferentes composições de $\mathrm{Fe}, \mathrm{O}$, Si e Al onde foi observado em valores de temperaturas entre 0 e $6000 \mathrm{C}$ a existência do complexo proposto por Morris e Barbour, (1973) e apoiado por Dukino,(1997) e representado no diagrama pela forma M3P . Todavia acima de $7000 \mathrm{C}$ em uma composição tendo valor máximo de $1,8 \%$ em massa de fósforo é demonstrada a não existência do complexo goetitafósforo devido a ocorrência da quebra de ligação entre o mineral goetita e o fosfato complexado ocorrendo assim a formação de hematita liberando o elemento fósforo no minério. Segundo Graham, (1973) a calcinação do minério de ferro causa desidratação da goetita para hematita, liberando o fósforo em solução como um composto solúvel em ácido.

Sendo assim Forssberg, et al (1981) investigaram a desfosforização com lixiviação ácida. Em seus estudos, foram utilizadas altas concentrações ácidas, todavia ocorreram baixas extrações de fósforo.

\subsection{Pré-Tratamento do Minério de Ferro Utilizando Energia de Microondas}

É observado através da Tabela 3 um rápido aumento de temperatura ocasionada na amostra de minério de ferro. Tal aumento é ocasionado devido ao fato da hematita conter propriedades ferromagnética possuindo assim forte interação com o campo magnético formado 
pelas microondas. O trabalho realizado por Roy e Agrawal (2001) mostrou que a interação do campo magnético com alguns materiais contribui muito na taxa de aquecimento comparado aos materiais expostos ao campo elétrico. Segundo Haque (1999) a energia de micro-ondas fornece um possível mecanismo para induzir a ruptura entre os minerais de valor no minério e a ganga, ou rocha hospedeira, devido ao diferencial na absorção de energia das micro-ondas e as diferenças térmicas dadas pelos coeficientes de expansão entre as várias fases minerais nas partículas do minério de ferro.

A aplicação de um campo magnético a uma substância diamagnética (com momento magnético nulo na ausência de campo) é responsável pela indução de um momento magnético cuja direção é oposta à do campo externo aplicado como demonstrado na Figura 4.

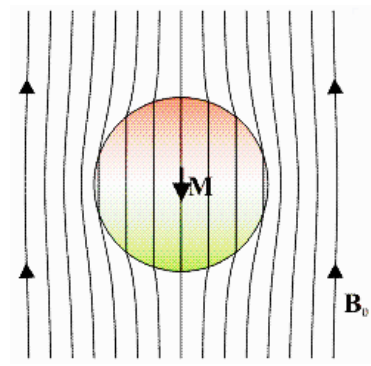

Figura 4. Direção do momento magnético das moléculas das substâncias diamagnéticas em relação ao campo magnético aplicado. Fonte: Universidade de Sevilla.

Este é um efeito exatamente oposto ao produzido pelo paramagnetismo, onde o dipolo magnético permanente tende a alinhar-se na mesma direção do campo externo. (OLIVEIRA, 2005) $\mathrm{Na}$ Figura 5 são apresentadas micrografias de minério de ferro de diferentes frações granulométricas.

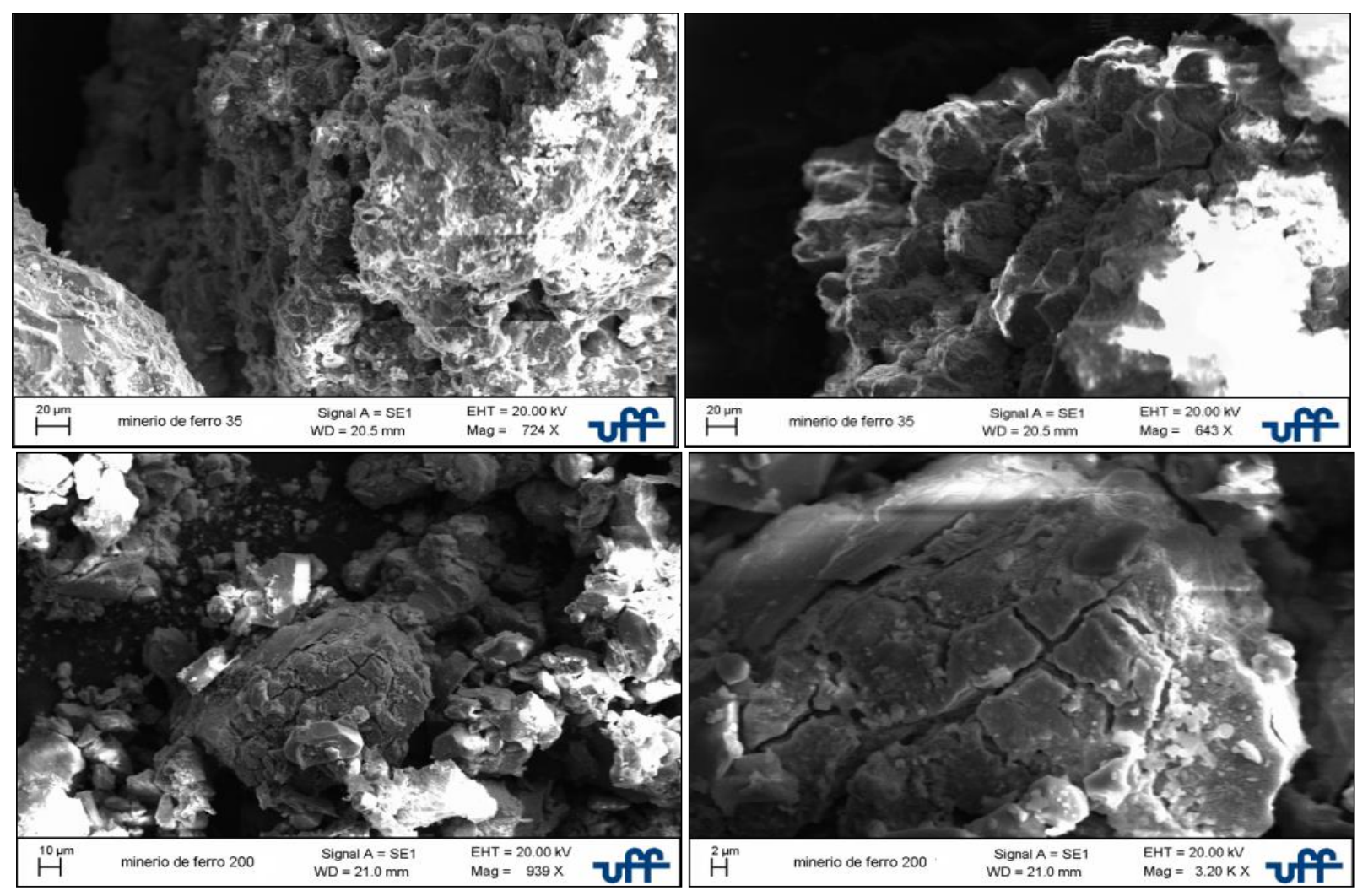

Figura 5. Micrografias do minério de ferro em 35 e $200 \mu \mathrm{m}$. 
$\mathrm{Na}$ Figura 5 é observada, através das imagens geradas por microscopia eletronica de varredura, a formação de porosidade nas partículas de minério de ferro em diferentes granulometrias.

3.3 Análise do perfil de aquecimento do minério de ferro em contato com a energia de micro-ondas

O aumento da temperatura do minério de ferro em contato com a energia de microondas é demonstrada na Figura 5, sendo demonstrado o tamanho granulométrico dado em escala mesh. (menores valores de mesh representam maiores tamanhos granulométricos)

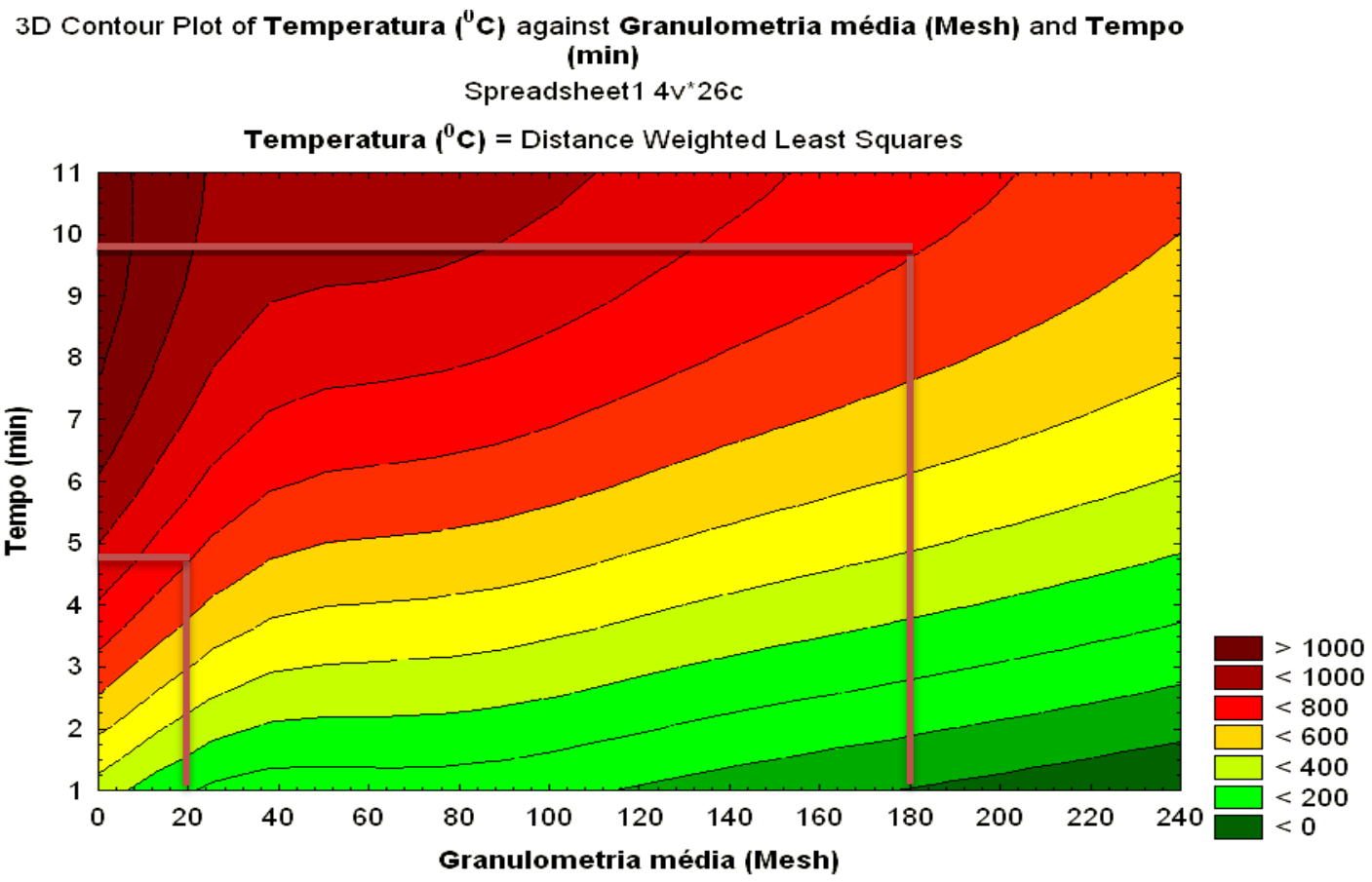

Figura 6. Aumento de temperatura do minério de ferro em função do aumento de granulometria e tempo.

3D Contour Plot of Temperatura $\left({ }^{\circ} \mathrm{C}\right)$ against Tempo (min) and Massa $(\mathrm{g})$

Spreadsheet $14 v^{\star} 26 c$

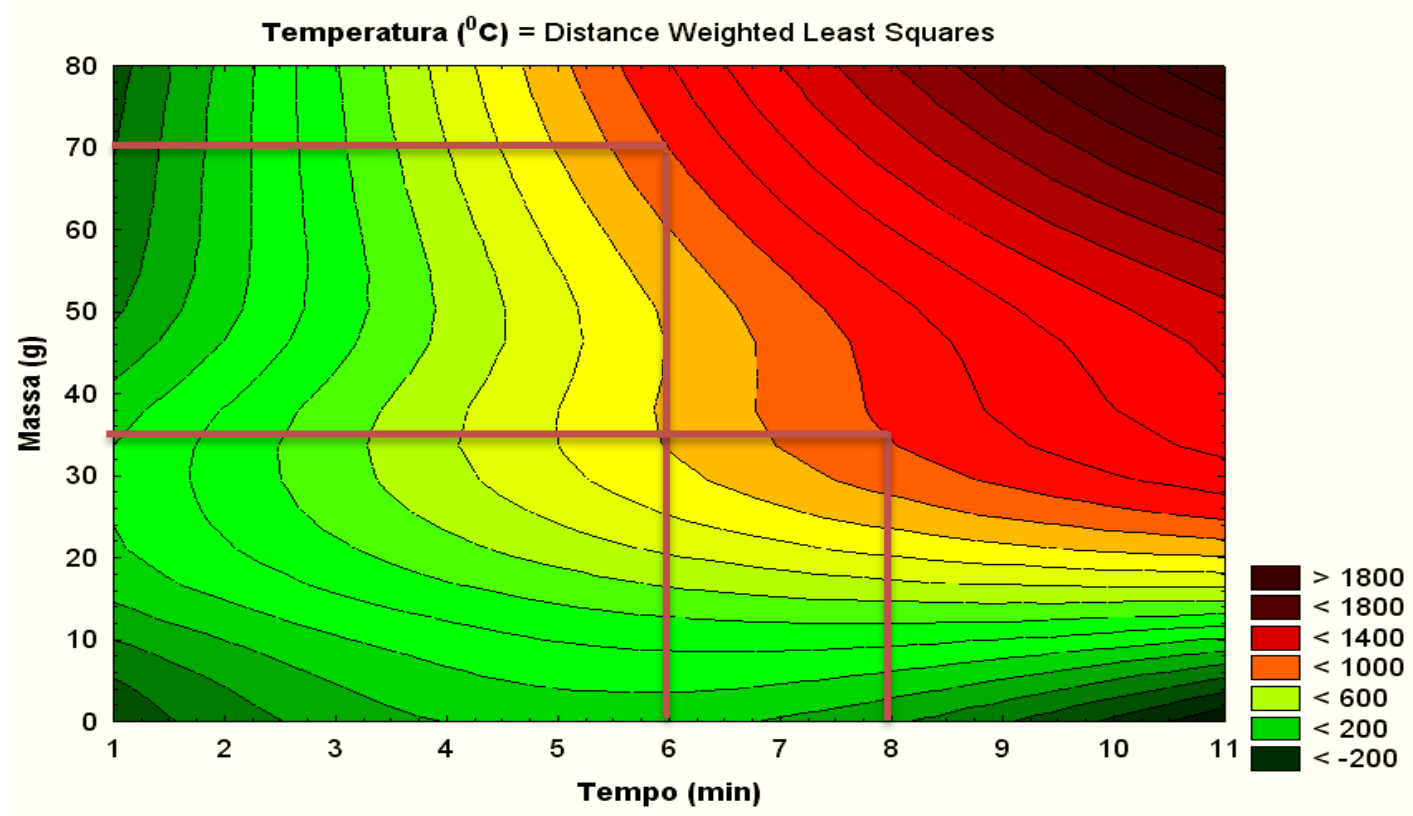

Figura 7. Aumento de temperatura da amostra de minério de ferro em função do aumento de massa e tempo. 
3D Contour Plot of Temperatura $\left({ }^{0} \mathrm{C}\right)$ against Granulometria média (Mesh) and Massa $(\mathrm{g})$

Spreadsheet $14 \mathrm{v}^{\star} 26 \mathrm{c}$

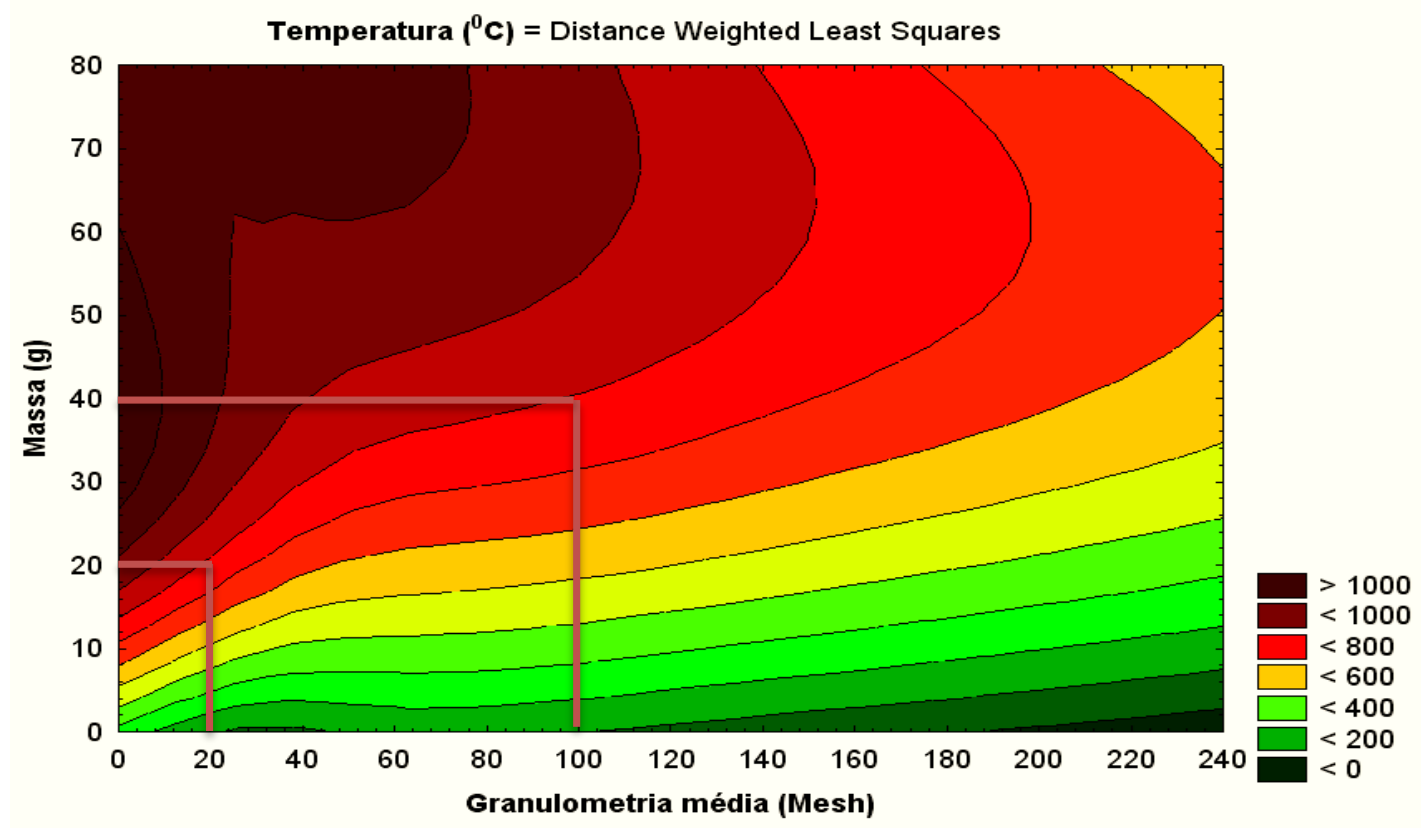

Figura 8. Aumento de temperatura da amostra de minério de ferro em função do aumento de massa e granulometria
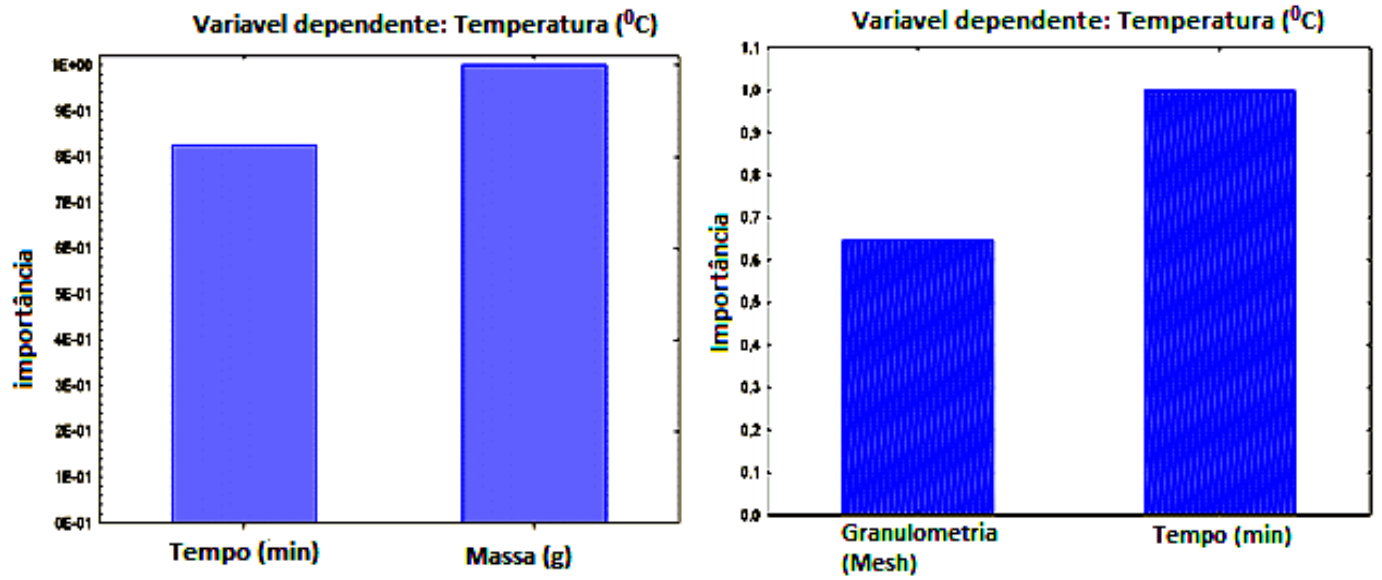

Figura 9. Relação de importância entre tempo, massa e tamanho granulométrico durante a realização dos ensaios.

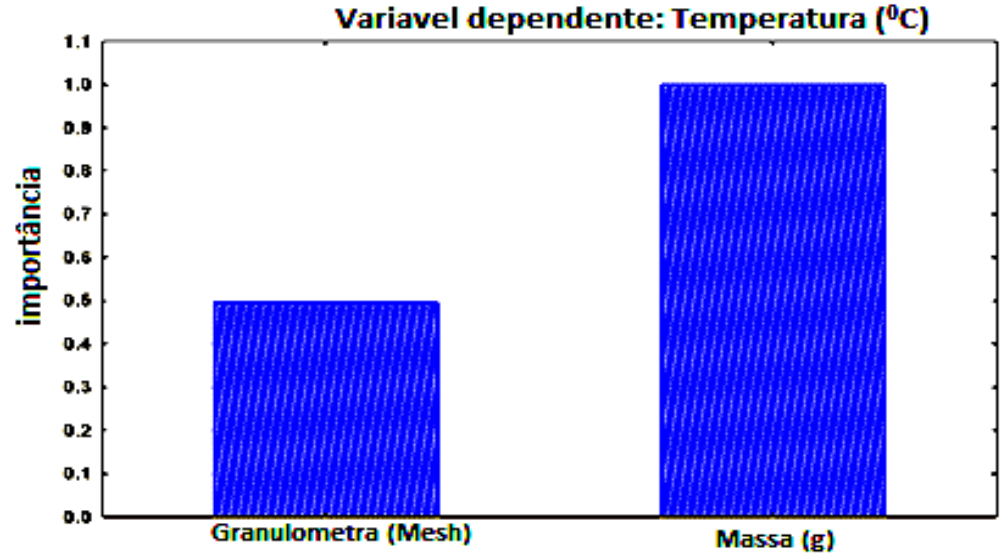

Figura 10. Relação de importância entre granulometria e massa durante a realização dos ensaios. 
Através da Figura 6 foi demonstrado o aumento de temperatura do minério de ferro em função das variáveis tamanho granulométrico e tempo sendo observado que o efeito do rápido aquecimento do minério de ferro ocorreu em função do aumento da variável tamanho granulométrico. Na Figura 7 é observado o aumento de temperatura da amostra de minério de ferro em função do aumento das variáveis massa e tempo onde foi observado que o efeito da redução no tempo de contato da amostra de minério de ferro ocorre em função do acrescimo da variável massa da amostra.

Grandes tamanhos granulométricos possuem grandes concentrações de magnetita e caulinita, tendo em vista a alta interação das moléculas de magnetita onde as quais geram um efeito de alinhamento em relação ao campo magnético e o efeito de interação oposta ocasionada pelas moléculas de quartzo torna-se possível explicar o aquecimento por atrito na partícula de minério de ferro. Na Figura 8 é demonstrado o aumento de temperatura da amostra de minério de ferro em função das variáveis massa e tamanho granulométrico sendo observado que o aumento de temperatura foi ocasionado em função do aumento das variáveis massa e tamanho granulométrico.

Na Figura 9 observa-se a relação de importância entre variável tempo, massa e tamanho granulométrico. Todavia durante a realização dos ensaios foi observado que para o aquecimento do minério de ferro, utilizando energia de microondas, o maior grau de importância é dado pela variável massa seguido da variável tamanho granulométrico. Na Figura 10 é demonstrada a relação de importância entre as variáveis tamanho granulométrico e massa sendo observado que durante a realização dos ensaios o maior grau de importância é dado ao aumento de massa da amostra de minério de ferro em relação ao tamanho granulométrico sendo tal fato explicado pelo aumento da quantidade de hematita e quartzo onde os quais provocarão aumento no atrito na partícula mineral aumentando assim a temperatura do minério de ferro. Walkiewicz et al. 1988, demonstraram que o aquecimento rápido do minério em contato com microondas ocorre devido a absorção de energia nos minerais constituidos em uma matriz de ganga não-absorventes gerado estresse térmico. Este estresse térmico causa microfraturamento ao longo do grão mineral limites, como resultado, tal amostra um minério torna-se mais emendável da moagem.

A utilização das microondas permite transferir a energia diretamente para dentro do material, onde é convertida em calor através da interação dos átomos e moléculas com o campo eletromagnético, em processos de condução iônica, relaxação dipolar, interação fotão-fotão. Assim, com micro-ondas é possível um aquecimento volumétrico do material, o que resulta na possibilidade de aplicação de altas taxas de aquecimento, reduzindo consideravelmente os tempos de processamento e sobrepondo uma série de dificuldades observadas em processos que utilizam técnicas convencionais de aquecimento rápido (MENEZES et.,al 2004).

Na Figura 11 é demonstrado o aquecimento da amostra de minério de ferro em diferentes massas e tamanhos granulométricos. 

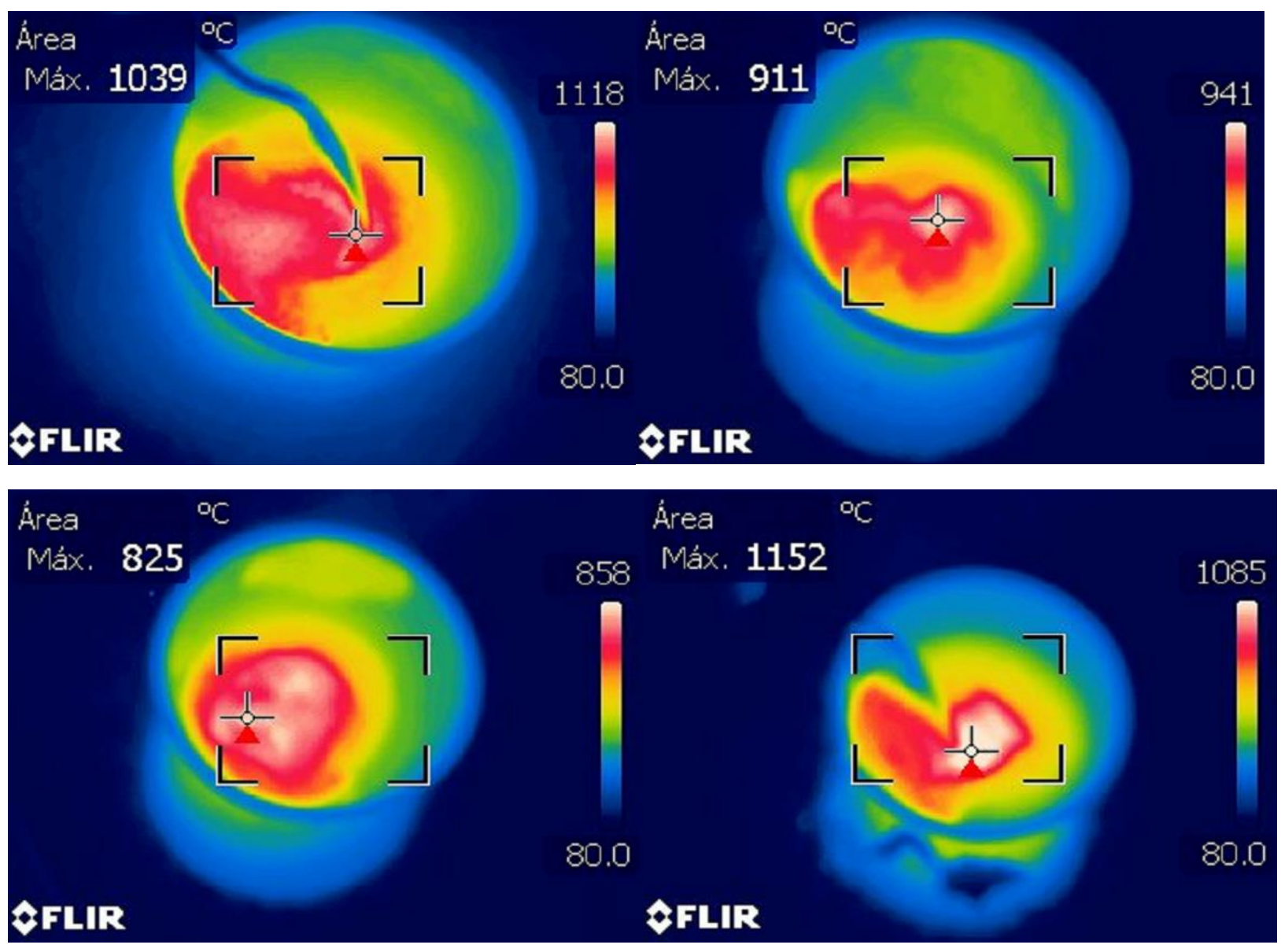

Figura 11. Aquecimento da amostra de minério de ferro em diferentes massas e tamanhos granulometricos.

\section{CONCLUSÕES}

Com a finalidade de estudar a remoção de fósforo em minério de ferro na região do quadrilátero ferrífero, Brasil, e tendo também o propósito de analisar o efeito das micro-ondas no minério de ferro em diferentes condições as seguintes conclusões foram tiradas:

O aquecimento rápido do minério de ferro ocorre em função do aumento do tamanho granulométrico e da massa de minério de ferro em contato com micro-ondas fato explicado pelo aumento da concentração de hematita onde a qual segue com o aumento de massa e granulometria. Contudo com o aumento de temperatura e posterior resfriamento em água à temperatura ambiente ocorre fraturas nas partículas de minério de ferro em diferentes granulometrias onde a qual podem propiciam maiores quebras durante o processamento de moagem fazendo assim que as partículas de minério cheguem mais rapidamente a granulometrias inferiores. Contudo pode-se concluir que o processo de remoção do fósforo em minério de ferro complexado com a goetita será altamente favorecido devido ao aquecimento do minério de ferro onde o qual ocorrerá um rearranjo do complexo formado entre a goetita e o fósforo liberando assim o mesmo para a solução lixiviante onde o mesmo devido a fraturas geradas através do choque térmico terá um aumento significativo na superfície de contato entre o mineral e a solução lixiviante. 
Não obstante é importante a realização de trabalhos futuros objetivando-se percentuais de remoção do elemento fósforo em partículas de minério de ferro após o aquecimento em energia de micro-ondas em diferentes massas e granulometrias.

\section{AGRADECIMENTO}

Os autores agradecem aos órgãos financiadores: Coordenação de Aperfeiçoamento de Pessoal de Nível Superior, Ministério da ciência e tecnologia. Agradecem também a equipe do Centro de Tecnologia Mineral pelo desenvolvimento dos ensaios e análises químicas e ao programa de pós-graduação em Engenharia Metalúrgica da Universidade Federal Fluminense pelo apoio técnico científico.

\section{REFERÊNCIAS BIBLIOGRÁFICAS}

1. BARBOUR, A.R. Distribution of phosphorus in iron ore deposit of Itabira, Minas Gerais, Brazil, Economic Geology, 1973, p. 11- 13.

2. DUKINO, R. Phosphorus in Hamersley Range iron ore, BHP Internal Report,USA, 1997

3. FORSSBERG R, ASOLFSSON G. Dephosphorisation of high-phosphorus iron ores by means of acid leaching. Erzmetal, p 316-322, 1981

4. GRAHAM, J. Phosphorus in iron ore from the Hamersley iron formations, Proceedings of the Australasian Institute of Mining and Metallurgy, No. 246, p. 41-42. 1973.

5. HAQUE K.E. Microwave energy for mineral treatment processes a brief review Int. J. Miner. Process. 57 (1999) 1-24

6. HAQUE, K.E. Unpublished data. CANMET, 555 Booth St., Ottawa, ON, K1A 0G1, Canada, 1998.

7. KRUG, F.J, Métodos de Decomposição de Amostras. 5ạ edição, São Paulo, V Workshop sobre Preparo de Amostras, 2004.

8. Menezes, R. R. Souto, P. M. Fagury-Neto, E. R.. Kiminami, H. G. A Proc. 4th World Cong. Microwave and Radio Frequency Appl., Eds. R. L Shulz, D. C. Folz, The Microwave Working Group, Arnold, MD (2004)

9. MORRIS, R.C., A pilot study of phosphorus distribution in parts of the Brockman iron formation, Hamersley Group Internal Report, 1973.

10. OLIVEIRA J.A.C Síntese de Hexaferrita de Bário Dopada com Cobalto-Titânio por Moagem Quimicamente Assistida Seguida de Calcinação Rio de Janeiro 2005

11. RODRIGUES, M.I, ANTONIO, F.I, planejamento de experimentos e otimização de processos, casa do pão editora 2005, 618p

12. ROY, R., AGRAWAL, D., PEELAMEDU,. Anisothermal Reaction Synthesis of Garnets, Ferrites, and Spinels in Microwave Field". Materials Research Bulletin, 2001

13. Walkiewicz, J.W., McGill, S.L., Moyer, L.A, 1988. Improved grindability of iron ores using microwave energy. Materials Research Society Symposium Proceedings (Microwave Process. Mater.) 124, 297-302. 